\title{
Solar assisted liquid desiccant cooling using clay based membranes
}

\author{
S. Shanmuga Priya ${ }^{1 *}$, Sneha Reddy ${ }^{1}$, Priyadarshini Balachandar ${ }^{1}$ and Sanober Wadhwania ${ }^{1}$ \\ ${ }^{1}$ Department of Chemical Engineering, Manipal Institute of Technology, Manipal Academy of Higher \\ Education, Manipal, Karnataka. India.
}

\begin{abstract}
The environmental concerns have led to the urge of the usage of non-conventional energy resources like solar, wind, thermal, geothermal etc. which provide enormous source of energy without causing any further diminution of the environment. Instead of the conventional HVAC systems that cause colossal environmental perils, usage of liquid desiccants in coming in vogue whereby reducing ecological threats. Moreover, solar assisted systems provide further impulse to such systems. This paper discusses about the various comparisons between liquid desiccants: Lithium chloride, Potassium formate and Calcium chloride and concludes that potassium formate is the best desiccant to be used among the three. Potassium formate (HCOOK) is used which is cheaper and less corrosive as compared to the other aqueous salts, and has a negative crystallization temperature. Potassium formate is a new liquid desiccant and thus, not much research is available currently. The weather conditions of Manipal provide an appropriate condition for the experimentations of solar aided liquid desiccant evaporative cooling systems due to its humid climate and intense solar radiation obtained. The small scale experimentation also encounters the problem of liquid desiccant carryover by the air flow, with the help of clay based membranes which are again cheap, environmentally benign and obtained in a facile way. The projected system takes complete advantage of pure solar energy aimed at the regeneration of liquid desiccant.
\end{abstract}

Keywords: Desiccant evaporative cooling - Solar - Liquid desiccant Clay based membrane

\section{Introduction}

The rapid increase in world population and economic development has led to the immense deterioration of conventional type of energies with increasing demand for human comfort conditions. The pollution caused by the conventional form of energies and their depletion has headed to the immediate call for alternatives. Hence immerging researches focus on the use of renewable form of energies as the alternative. The usage of air conditioning and heating devices shows a notable role in the emanation of chlorofluorocarbons which causes exhaustion of ozone layer and other environmental concerns. Research is being carried out

\footnotetext{
* Corresponding author: shan.priya@manipal.edu
} 
in order to decrease the dependency of dehumidification technology on non-renewable resources.

Lowenstein et al. [1] studied on the solar assisted liquid desiccant cooling systems and thereby developed and commercialized a novel design of a liquid desiccant systems to dry and cool supply air of building air conditioners. The new system has a desiccant flooding rate with the factor of 10 to 20 lower than the rates of the presently used conventional packed bed systems which provides a compact system that deeply dries the process air having much lower pressure drop, higher COP and greater cooling effect. Shahab Alizadeh [2] performed the feasibility analysis of a solar assisted liquid desiccant air conditioner developed in Queensland. The arrangement customs an absorber unit of cross flow polymer plate heat exchanger that dries the process air with greater efficiency. The study reveals higher air temperature and relative humidity control on a commercial site of 120 sq. $\mathrm{m}$ area in Brisbane. K. Gommed and G. Grossman [3] studied on solar cooling and dehumidification using liquid desiccant and low cost flat plate collectors. Considering several cycle variations, they concluded that the heat and mass transfer in the dehumidification process are considerably affected by the conditions of the inflowing ambient air. They also concluded that the temperature and flow rates of cooling and heating water and the flow rates of the solution through the absorber and regenerator affect the humidity level of the conditioned space. Nia et al. [4] adopted a new approach to study and compare between solid and liquid desiccant cooling systems and concluded that liquid desiccant systems are relatively large without technology improvements, but have lower COP with low capacities on comparison to solid desiccant systems. Mei and Dai [5] reviewed on liquid desiccant dehumidification for air-conditioning applications and concluded that liquid desiccants and easily grasp the humidity ratio, independent control and temperature although they have drawbacks of unstable operation and large dimension. They also concluded that the climatic changes of ambient air condition and solar insolation, hamper in the continuous operation of such systems. Katejanekarn et al. [6] did an experiment on a solar-regenerated liquid desiccant ventilation pre-conditioning system during a period of nine months covering all seasons in the hot and humid climatic conditions of Thailand. Their study reveals that the system could decrease the temperature of the supplied air by about $1.2 \mathrm{C}$ while the humidity ratio was reduced by 0.0042 $\mathrm{kgw} / \mathrm{kgda}$ equivalent to $11.1 \%$ relative humidity reduction. P. Gandhidasan [7] implemented the examination of a solar spaced cooling system using liquid desiccant for ventilation mode and derived an expression to calculate the amount of heat removal from the room to be conditioned through a simplified vapour compression correlation using some known initial parameters. He also conferred the effect of cooling water temperature, ambient air conditions, solution concentration, the efficacy of the dehumidifier and the heat exchanger on the performance of the cooling system. Josh and Jane [8] studied a liquid desiccant storage tank's buoyancy driven mass transfer based on the absorption properties of aqueous calcium chloride for the long term solar thermal storage. The experimentation for certain buoyancy ratios and Rayleigh's numbers produce the corresponding Sherwood numbers needed. Yin and Zang [9] illustrated a relative learning on internally heated and adiabatic regenerators in liquid desiccant air conditioning system and established that internally heated regenerator demonstrated high energy utilization efficiency and could escalate the rate of regeneration. Also, that they can provide comparable regeneration efficiencies and rate of regeneration at lower desiccant flow rates hence proving to be a good alternative to avoid liquid desiccant carryover as compared to adiabatic regenerators. K. Daou et al. [10] reviewed on desiccant air conditioning systems and revealed the feasibility of them in various climatic conditions to prove the benefits offered by them in terms of cost and energy savings. Armando et al. [11] conducted research on novel 
approach to liquid desiccant assisted cooling for humid environments showing that similar systems have potential to compete with conventional air conditioning units while also being more cost effective and efficient. Li Zhang et al. [12] did general research on a hybrid air cooling system using a liquid desiccant. They found that they received an overall $10 \%$ increase in efficiency when the liquid desiccant was used to assist in the cooling process. Zhen Li et al. [13] applied a similar method in a hospital facility in Beijing. They found that along with increased energy efficiency of a desiccant assisted system, they also established a higher quality of air by using more fresh air and using the desiccant to sterilize and clean the air. Huang and Zhang [14] researched on membranes aided in liquid desiccant systems to avoid the carry-over of the liquid desiccant in the air cooling systems. The review collected the data on the recent transport data of various membrane modules and discussed in details about the different types of membranes and several materials used for the membranes. They concluded that the use of membranes was a good option but future work may include multiple stage membrane configuration and a cooling coil in the configuration to offer locally cooling membrane based dehumidifier. Chen et al. [15] executed the experimental analysis on the performance assessment of liquid desiccant dehumidifier and cooling system aided with membrane using calcium chloride solution as the desiccant. They concluded that the performance of the dehumidifier is solely influenced by ambient weather conditions and an increase in cooling output and decrease in effectiveness of the dehumidifier is observed with the increase in the flow rate of air.

After understanding the basics and carrying out a brief literature review, it was observed that calcium chloride and lithium chloride are the most suitable liquid desiccants. They have large saturation absorption capacity, low regeneration temperature, low viscosity, and high heat transfer rate thus they were chosen for experimentation. The performance efficiency of the chosen liquid desiccant was calculated by using the wetted wall column apparatus. Here, the dry bulb and wet bulb temperatures were recorded to find the relative humidity from the psychometric chart.

\section{Materials and methods}

A clay based membrane was prepared by size reduction followed by drying for a stipulated period of time. Sodium meta silicate, boric acid and sodium carbonate were added to enhance the properties of the membrane. A parabolic trough solar collector is used for the regeneration of the weak desiccant.

Scanning electron microscopic analysis was carried out for the clay based membrane to determine the nature of the membrane. Different desiccants were used as the liquid medium in the wetted wall column set-up. Relative and absolute humidity of the chosen desiccants were determined and compared.

An experimental setup was fabricated that provides dehumidification and air cooling. Efficiencies of the different liquid desiccants were calculated and compared with the values obtained from wetted wall column setup. Performance effectiveness of membrane aided liquid desiccant system was done.

\subsection{Preparation of Clay based membrane}

Soil brought was dried at $100^{\circ} \mathrm{C}$ for $24 \mathrm{hrs}$ for complete removal of moisture. Then it was crushed with pestle and mortar to remove agglomerations and chucks of sand. This soil was then fed into a ball mill, crushed to fine powder and was sieved with BSS 36 mesh screen 
sieve to segregate coarse particles. The obtained powder was kept in an air tight container to avoid moisture and stored in a cool, dry place.

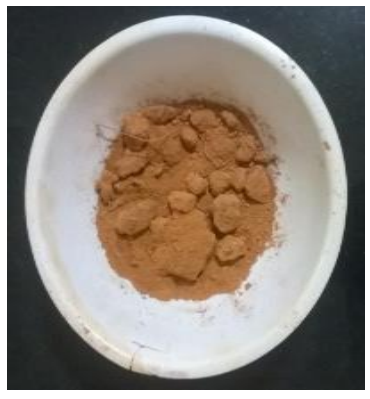

(a)

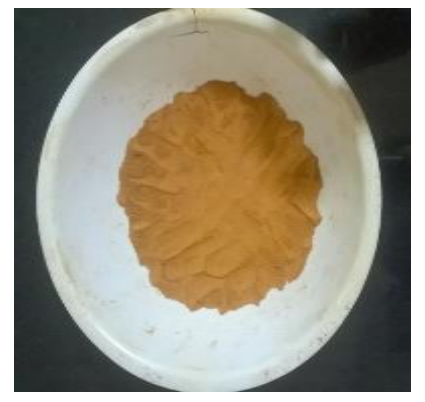

(b)

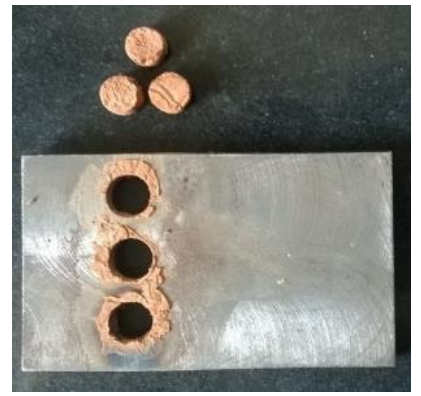

(c)

Fig. 1. Fabrication of clay based membrane

Fig 1 (a) depicts a sample of the coarse sand that was further processed for the membrane fabrication. Fig 1(b) shows the sand after size reduction techniques. Fig 1 (c) shows the membrane samples in the pellet form.

Low-cost ceramic-based membrane support was arranged. The membrane was prepared by paste casting from the composition of the given materials: clay $(70 \%)$, sodium carbonate (3\%), Sodium meta silicate (1.5\%), and Boric acid (1.5\%). The ingredients were made into a paste with distilled water(24\%) and was casted over an aluminum foil in the shape of a circular molds. After restricted drying in room temperature for $24 \mathrm{hrs}$, the disc was removed carefully and heated at $373 \mathrm{~K}$ for 12 hours. The cast disc was heated at $1123 \mathrm{~K}$ for 3 hours. in a furnace. Temperature of the furnace was gradually ventilated to room temperature. The support was finally polished with silicon carbide abrasive paper(C-180), to give it a final form. Sodium meta silicate increases mechanical strength by creating silicate bonds. Boric acid also increases mechanical strength by creating metaborates during sintering. Sodium carbonate improves dispersion properties, thereby creating homogeneity.

\subsection{Experimental Unit}

A liquid desiccant dehumidification system comprises of an absorber and a regenerator. Inside the dehumidifier, the liquid desiccant absorbs moisture to dehumidify the hot and humid process. A cuboidal shaped container is used for storing the liquid desiccant, to which a fan is attached on one end to draw the hot and humid air. The other end has a combination of fan, heat sink and peltier cooler to cool and dehumidify the air. Lithium chloride and potassium formate are the two desiccants used in this experimental study. Potassium formate is chosen because it is less corrosive and more economical. Lithium chloride is one of the most commonly used desiccants. A comparative study is made between the two desiccants. The weak desiccant flows from the absorber to a flat plate collector. The solar energy is used to evacuate the moisture trapped in the desiccant. The weak desiccant is heated to an elevated temperature so as to remove the moisture absorbed by it.

The ambient room temperature was measured. The peristaltic pumps were switched on to circulate the liquid desiccant through the solar collector. This is done in order to regenerate the liquid desiccant. Power supply is provided to the set up and humid air is 
drawn in. After a certain time interval, temperature of the hot air at the heat sink and the temperature of the cool air at the peltier cooler are measured. These values are used to measure the percentage humidity and the relative humidity of the air stream.

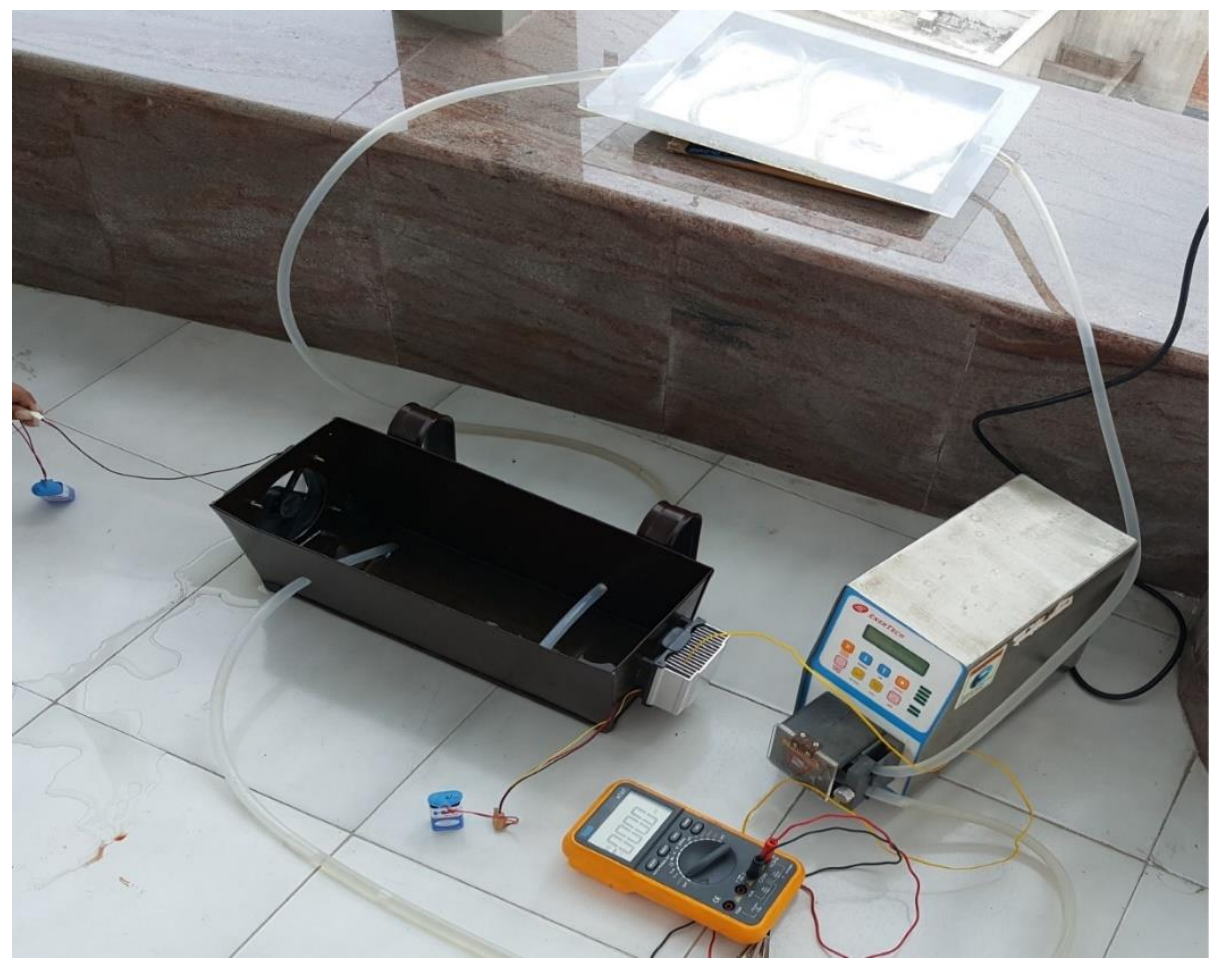

Fig. 2. Experimental set up

The main experimental setup shown in Fig 2 consists of a fan which draws in the hot humid air from outside, a rectangular box which has liquid desiccant to absorb the moisture from the air. On the other side of the box there is a system of fan, heat sink and peltier cooler which draws the heat from the air thus making it cooler. The used desiccant flows to the regenerator which is the flat plate solar collector where the moisture is removed and the desiccant is renewed. Peristaltic pumps are used to force the desiccant to flow through the solar collector.

The multimeter gives us the voltage across the junctions which can be used to determine the temperature of air inside the experimental unit. The fans are attached for inlet and outlet. The fans are powered with normal $12 \mathrm{~V}$ batteries. The container holds the desiccant and is connected with pump and the solar collector with pipes for desiccant regeneration. The peristaltic pump was used to circulate the desiccant to solar collector and back to the desiccant storage unit. 


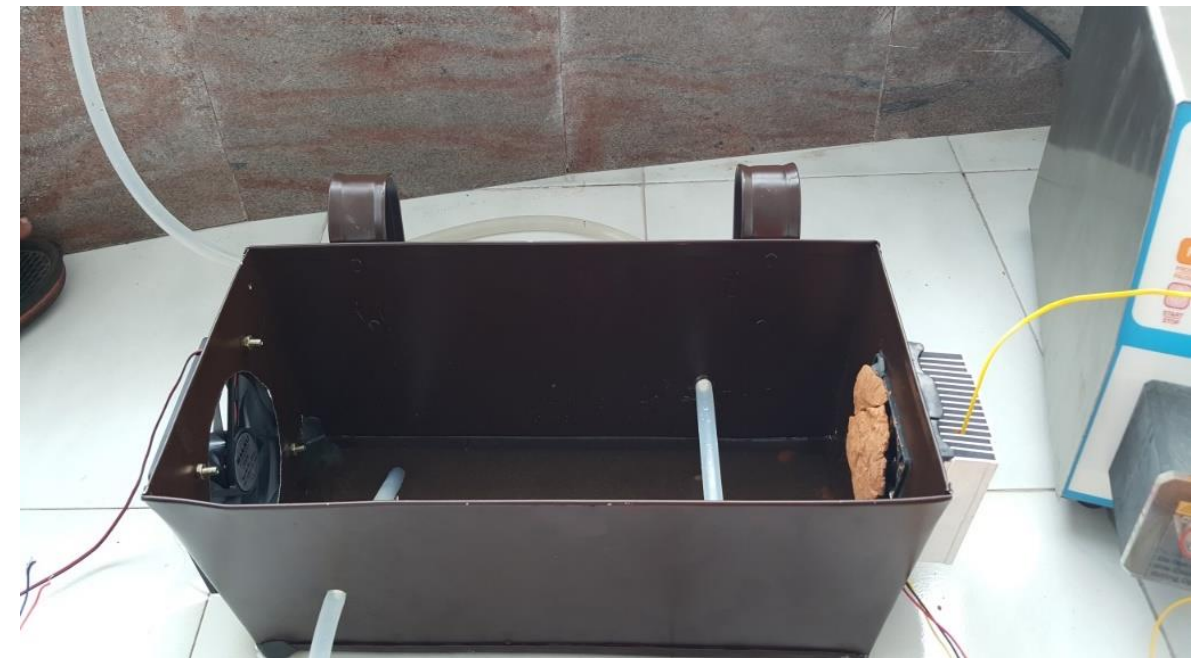

Fig. 3. Experimental Setup with the membrane

The Fig 3 shows the setup with the membrane which helps preventing the carryover.

\section{Results and discussion}

\subsection{Clay based membrane}

The micro-porous clay membrane was fabricated as given in the methodology above. The sample, in a pellet form was given for scanning electron microscope (SEM) analysis.

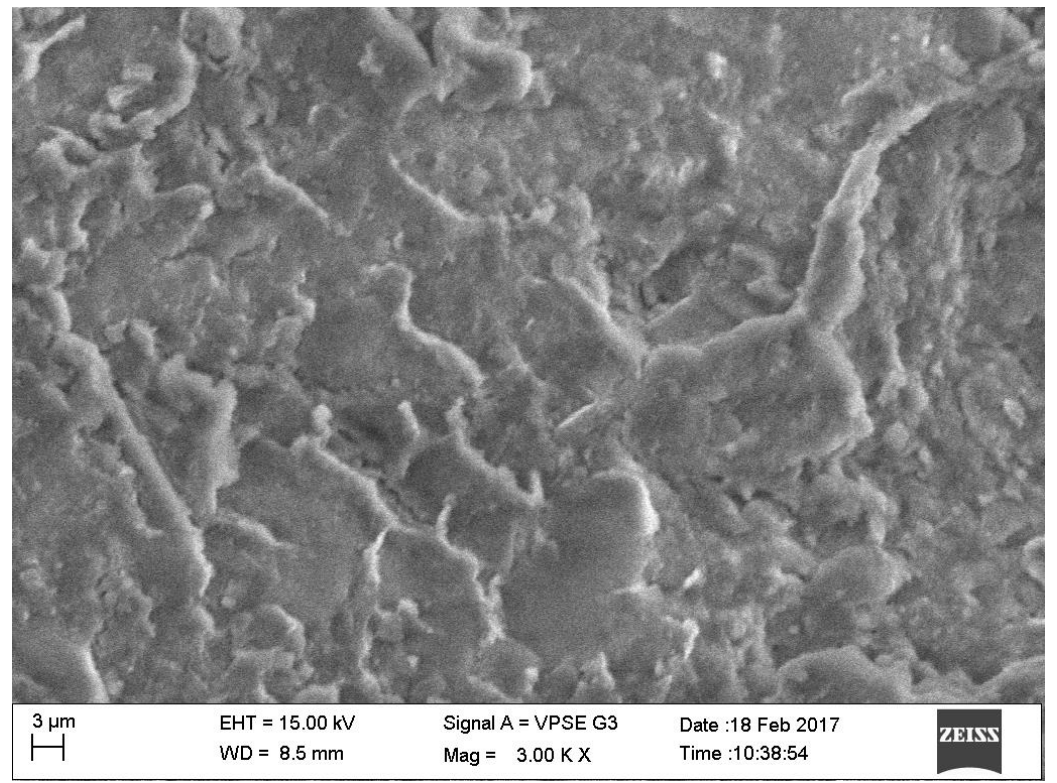

Fig. 4(a). $3 \mu \mathrm{m}$ SEM analysis 


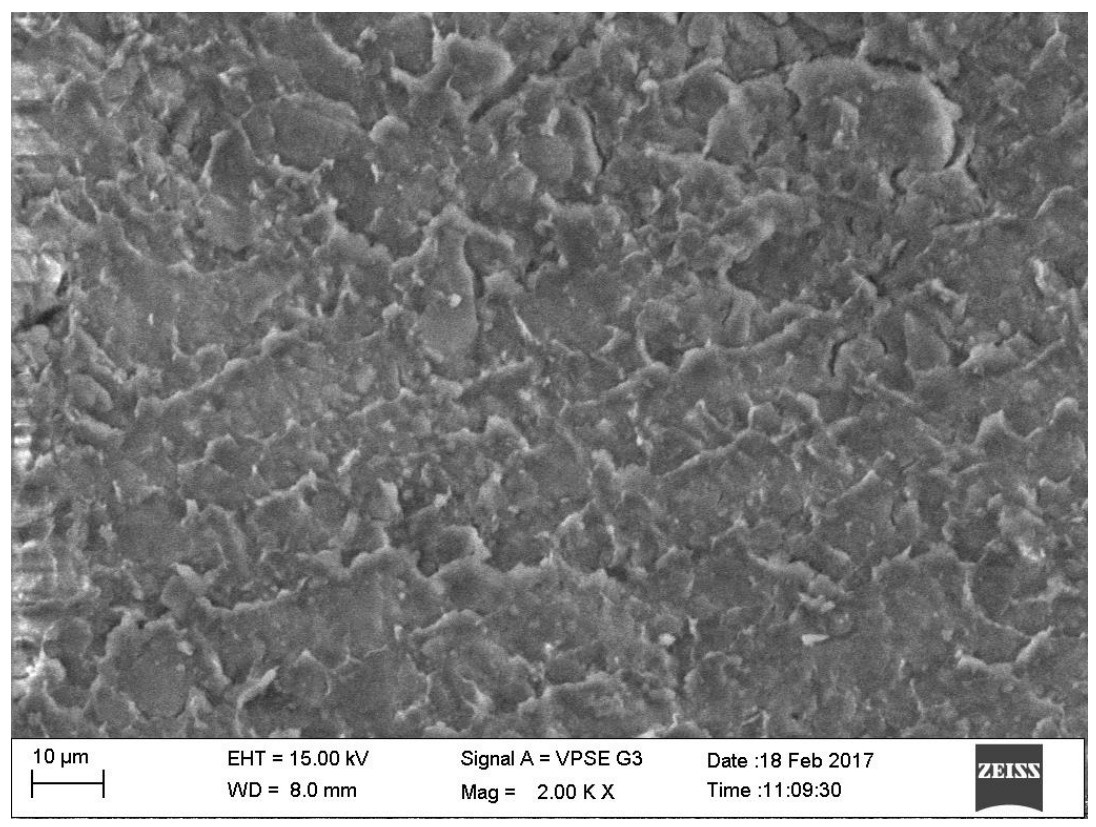

Fig. 4(b). $10 \mu \mathrm{m}$ SEM analysis

Fig $4 \mathrm{a}$ and $4 \mathrm{~b}$ shows the porous structure of the clay based membrane obtained by the scanning electron microscopic analysis of $3 \mu \mathrm{m}$ and $10 \mu \mathrm{m}$ respectively.

Table 1. ImageJ results of Scanning Electron Microscope images

\begin{tabular}{|l|l|l|l|l|}
\hline Trial & Label & Area & Mean & \%Area \\
\hline 1 & CBM-2-07 & 703488 & 106.756 & 7.541 \\
\hline 2 & CBM-2-04 & 703488 & 134.579 & 12.66 \\
\hline 3 & CBM-2-09 & 671775 & 97.737 & 12.804 \\
\hline 4 & CBM-1-02 & 697330 & 127.675 & 12.973 \\
\hline 5 & CBM-2-10 & 705180 & 97.247 & 13.59 \\
\hline 6 & CBM-1-06 & 702801 & 97.646 & 17.316 \\
\hline 7 & CBM-1-08 & 697343 & 169.21 & 19.792 \\
\hline 8 & CBM-2-06 & 697680 & 102.268 & 21.492 \\
\hline 9 & CBM-2-11 & 697004 & 90.936 & 22.309 \\
\hline 10 & CBM-1-13 & 695301 & 115.33 & 35.065 \\
\hline
\end{tabular}

In Table 1, area refers to the area of the sample that has been taken into consideration for the measurement of porosity. \% Area refers to the percentage of the area that is porous/empty in nature. 


\subsection{Efficiency of solar flat plate collector}

The set up consists of an aluminium solar collector with a silicon tube having high heat tolerance that allows the water to flow through and get heated.

The following procedure was adapted to calculate the efficiency of the collector. First the ambient air temperature was measured, then the pipes were filled with water and at different intervals of time the rise in temperature was measured. Efficiency of the flat plate solar collector was measured using the formula:

$$
\eta=[m \times C p \times(T-T a)] /[A \times H b \times t]
$$

where:

$$
\begin{aligned}
& \eta=\text { Efficiency of the collector } \\
& \mathrm{m}=\text { Mass of the water in the pipe in } \mathrm{kg} \\
& \mathrm{C}_{\mathrm{p}}=\text { Specific heat in } \mathrm{kJ} / \mathrm{kgK} \\
& \mathrm{T}=\text { Temperature of water in the pipe in } \mathrm{K} \\
& \mathrm{T}_{\mathrm{a}}=\text { Temperature of ambient air in } \mathrm{K} \\
& \mathrm{A}=\text { Collector area in } \mathrm{m}^{2} \\
& \mathrm{H}_{\mathrm{b}}=\text { Intensity of solar radiation in } \mathrm{W} / \mathrm{m}^{2} \\
& \mathrm{t}=\text { Time in } \mathrm{s}
\end{aligned}
$$

Table 2. Efficiency of flat plate collector

\begin{tabular}{|c|c|c|c|c|}
\hline TRIAL & $\begin{array}{c}\text { VOLUME } \\
(\mathrm{l})\end{array}$ & $\begin{array}{c}\text { TIME } \\
(\mathrm{s})\end{array}$ & $\begin{array}{c}\text { TEMPERATURE } \\
\left({ }^{\circ} \mathrm{C}\right)\end{array}$ & $\begin{array}{c}\text { EFFICIENCY } \\
(\%)\end{array}$ \\
\hline 1 & $1.50 \mathrm{E}-05$ & 6 & 42 & 5.064 \\
\hline 2 & $1.50 \mathrm{E}-05$ & 12 & 44 & 6.076 \\
\hline 3 & $1.50 \mathrm{E}-05$ & 18 & 45 & 6.583 \\
\hline 4 & $1.50 \mathrm{E}-05$ & 24 & 46 & 7.089 \\
\hline 5 & $1.50 \mathrm{E}-05$ & 30 & 46 & 7.089 \\
\hline
\end{tabular}

Table 2 shows that the efficiencies of the solar flat plate collector generally used is about $50-60 \%$ but since we are using a scaled down version of the model the efficiencies lie between $5-7 \%$. Given parameters are $\mathrm{T}_{\mathrm{a}}$ as $32^{\circ} \mathrm{C}, \mathrm{C}_{\mathrm{p}}$ as $4200 \mathrm{~J} / \mathrm{kgK}, \mathrm{H}_{\mathrm{b}}$ as $650 \mathrm{~W} / \mathrm{m}^{2}, \mathrm{~A}_{\mathrm{c}}$ as $0.0638 \mathrm{~m}^{2}$ and $\rho$ as $1000 \mathrm{~kg} / \mathrm{m}^{3}$. The lower efficiencies would not make a difference on the model's efficiency as it will be a continuous operation.

\subsection{Experiment with Calcium chloride:}

Dry bulb temperature $\left({ }^{\circ} \mathrm{C}\right)=\quad 41.00$ 
Wet bulb temperature $\left({ }^{\circ} \mathrm{C}\right)=\quad 36.00$

Relative humidity $(\%) \quad=\quad 64.00$

$\mathrm{P}_{\mathrm{ws}}(\mathrm{kPa}) \quad=\quad 4.33$

$\mathrm{P}_{\mathrm{w}}(\mathrm{kPa}) \quad=\quad 4.55$

Absolute humidity $\left(\mathrm{g} / \mathrm{m}^{3}\right)=\quad 29.90$

Table 3. Experimental observations- Calcium chloride

\begin{tabular}{|l|l|l|l|l|l|l|l|}
\hline Trial & $\begin{array}{l}\text { Voltage } \\
(\mathrm{mV})\end{array}$ & $\begin{array}{l}\text { Dry bulb } \\
\text { Temperature } \\
\left({ }^{\circ} \mathrm{C}\right)\end{array}$ & $\begin{array}{l}\text { Wet bulb } \\
\text { Temperature } \\
\left({ }^{\circ} \mathrm{C}\right)\end{array}$ & $\begin{array}{l}\text { Relative } \\
\text { Humidity } \\
(\%)\end{array}$ & $\begin{array}{l}\text { Absolute } \\
\text { humidity } \\
\left(\mathrm{g} / \mathrm{m}^{3}\right)\end{array}$ & $\begin{array}{l}\mathrm{P}_{\mathrm{ws}} \\
(\mathrm{kPa})\end{array}$ & $\begin{array}{l}\mathrm{P}_{\mathrm{w}} \\
(\mathrm{kPa})\end{array}$ \\
\hline 1 & 1.96 & 37.20 & 33.20 & 42.00 & 22.00 & 3.15 & 3.98 \\
\hline 2 & 1.98 & 37.50 & 33.50 & 43.00 & 23.38 & 3.35 & 4.16 \\
\hline 3 & 1.95 & 37.00 & 33.00 & 42.00 & 22.02 & 3.15 & 3.99 \\
\hline 4 & 1.94 & 36.73 & 32.73 & 41.00 & 20.99 & 3.00 & 3.86 \\
\hline 5 & 1.93 & 36.52 & 32.52 & 41.00 & 21.00 & 3.00 & 3.87 \\
\hline
\end{tabular}

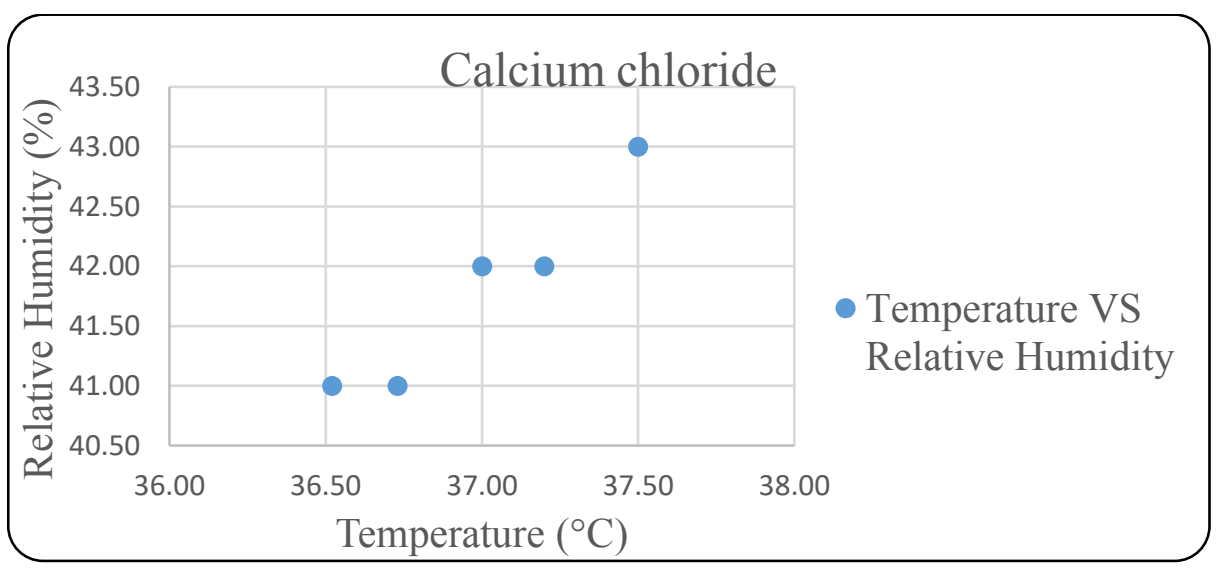

Fig. 5. Relative humidity VS Temperature - Calcium chloride

From the above table 3 and graph of fig. 5 it can be inferred that calcium chloride, as a desiccant allows a drop in humidity by $20 \%$. Greater the temperature drop, lower is the relative humidity. Errors in the above results can be due to improper control of flowrates and measurement. 


\subsection{Experiment with Lithium chloride}

$\begin{array}{lll}\text { Dry bulb temperature }\left({ }^{\circ} \mathrm{C}\right) & = & 41.00 \\ \text { Wet bulb temperature }\left({ }^{\circ} \mathrm{C}\right) & = & 36.00 \\ \text { Relative humidity }(\%) & = & 64.00 \\ \text { Pws }(\mathrm{kPa}) & = & 4.33 \\ \mathrm{Pw}(\mathrm{kPa}) & = & 4.55 \\ \text { Absolute humidity }\left(\mathrm{g} / \mathrm{m}^{3}\right) & = & 29.90\end{array}$

Table 4. Experimental observations- Lithium chloride

\begin{tabular}{|l|l|l|l|l|l|l|l|}
\hline Trial & $\begin{array}{l}\text { Voltage } \\
(\mathrm{mV})\end{array}$ & $\begin{array}{l}\text { Dry bulb } \\
\text { Temperature } \\
\left({ }^{\circ} \mathrm{C}\right)\end{array}$ & $\begin{array}{l}\text { Wet bulb } \\
\text { Temperature } \\
\left({ }^{\circ} \mathrm{C}\right)\end{array}$ & $\begin{array}{l}\text { Relative } \\
\text { Humidity } \\
(\%)\end{array}$ & $\begin{array}{l}\text { Absolute } \\
\text { humidity } \\
\left(\mathrm{g} / \mathrm{m}^{3}\right)\end{array}$ & $\mathrm{P}_{\mathrm{ws}}(\mathrm{kPa})$ & $\begin{array}{l}\mathrm{P}_{\mathrm{w}} \\
(\mathrm{kPa})\end{array}$ \\
\hline 1 & 2.13 & 40.20 & 36.20 & 60.00 & 35.28 & 5.10 & 5.09 \\
\hline 2 & 2.14 & 40.50 & 36.50 & 59.00 & 35.59 & 5.15 & 5.18 \\
\hline 3 & 2.09 & 39.50 & 35.50 & 58.50 & 32.94 & 4.75 & 4.85 \\
\hline 4 & 2.08 & 39.20 & 35.20 & 58.00 & 29.50 & 4.25 & 4.37 \\
\hline 5 & 1.95 & 37.00 & 33.00 & 41.00 & 22.02 & 3.15 & 4.04 \\
\hline
\end{tabular}

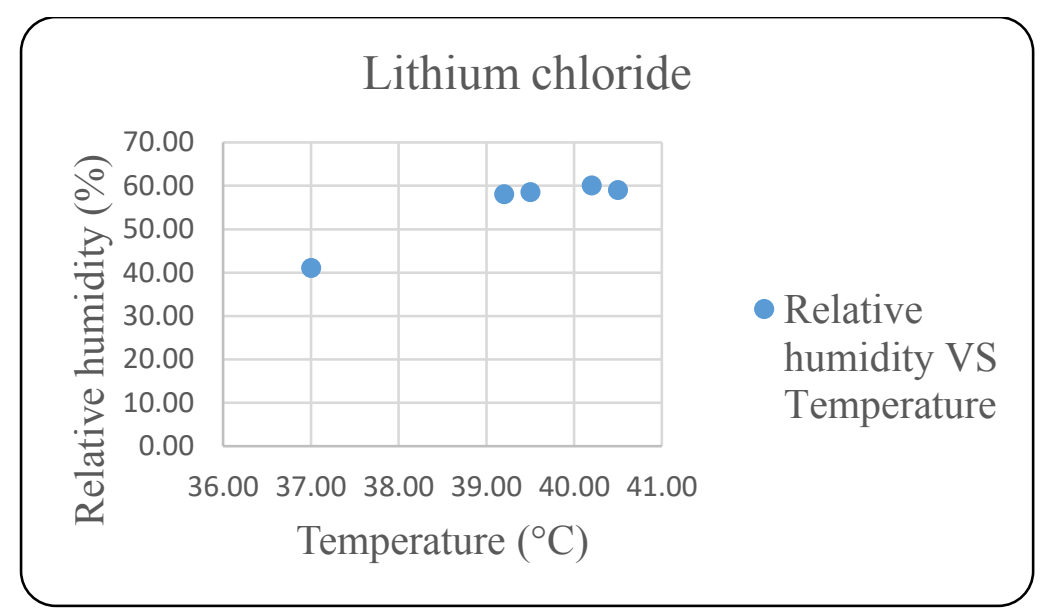

Fig. 6. Relative humidity VS Temperature - Lithium chloride

From tables 4 and graph of fig.6, it can be inferred that lithium chloride, as a desiccant allows a drop in humidity by about $7 \%$. Greater the temperature drop, lower is the relative humidity. Errors in the above results can be due to improper control of flowrates and measurement. 


\subsection{Experiment with Potassium formate}

$\begin{array}{lll}\text { Dry bulb temerature }\left({ }^{\circ} \mathrm{C}\right) & = & 41.00 \\ \text { Wet bulb temperature }\left({ }^{\circ} \mathrm{C}\right) & = & 36.00 \\ \text { Relative humidity }(\%) & = & 64.00 \\ \text { Pws }(\mathrm{kPa}) & = & 4.33 \\ \mathrm{Pw}(\mathrm{kPa}) & = & 4.55 \\ \text { Absolute humidity }\left(\mathrm{g} / \mathrm{m}^{3}\right) & = & 29.90\end{array}$

Table 5. Experimental observations- Potassium formate

\begin{tabular}{|l|l|l|l|l|l|l|l|}
\hline Trial & $\begin{array}{l}\text { Voltage } \\
(\mathrm{mV})\end{array}$ & $\begin{array}{l}\text { Dry bulb } \\
\text { Temperature } \\
\left({ }^{\circ} \mathrm{C}\right)\end{array}$ & $\begin{array}{l}\text { Wet bulb } \\
\text { Temperature } \\
\left({ }^{\circ} \mathrm{C}\right)\end{array}$ & $\begin{array}{l}\text { Relative } \\
\text { Humidity } \\
(\%)\end{array}$ & $\begin{array}{l}\text { Absolute } \\
\text { humidity } \\
\left(\mathrm{g} / \mathrm{m}^{3}\right)\end{array}$ & $\begin{array}{l}\mathrm{P}_{\mathrm{ws}} \\
(\mathrm{kPa})\end{array}$ & $\begin{array}{l}\mathrm{P}_{\mathrm{w}} \\
(\mathrm{kPa})\end{array}$ \\
\hline 1 & 2.02 & 38.30 & 34.30 & 58.00 & 30.97 & 4.45 & 4.62 \\
\hline 2 & 2.00 & 37.90 & 33.90 & 55.00 & 29.62 & 4.25 & 4.57 \\
\hline 3 & 2.01 & 38.20 & 34.20 & 57.00 & 30.29 & 4.35 & 4.57 \\
\hline 4 & 1.99 & 37.85 & 33.85 & 55.00 & 27.19 & 3.90 & 4.20 \\
\hline 5 & 1.98 & 37.75 & 33.75 & 54.00 & 26.15 & 3.75 & 4.09 \\
\hline
\end{tabular}

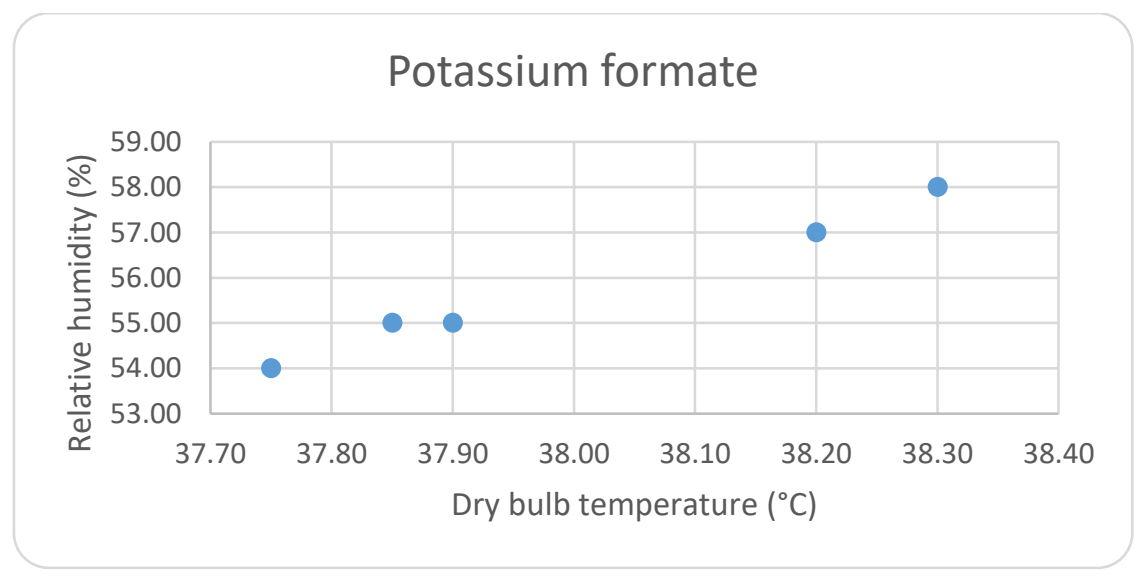

Fig. 7. Relative humidity VS Temperature - Potassium formate

From tables 5 and graph of fig.7, it can be inferred that potassium formate, as a desiccant allows a drop in humidity by $9 \%$. Greater the temperature drop, lower is the relative humidity. Errors in the above results can be due to improper control of flowrates and measurement. 


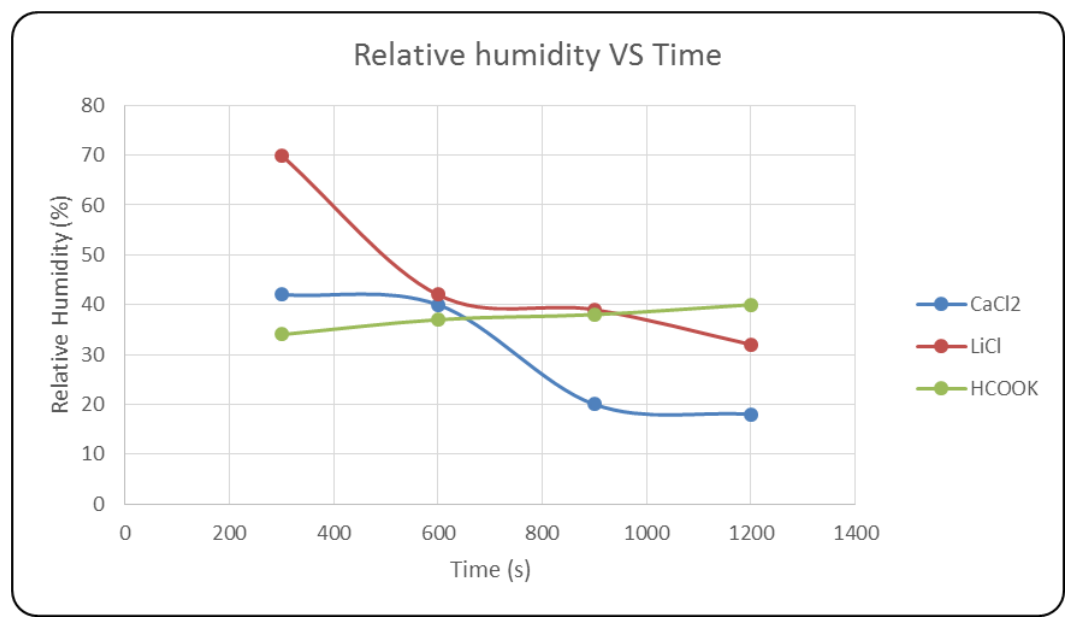

Fig. 8. Comparison of different desiccants with respect to relative humidity

The above graph shows the dehumidification property of the three desiccants with respect to time. Though calcium chloride and lithium chloride show a decrease in relative humidity, potassium formate has been chosen because it is less corossive than the rest. It has been studied that potassium formate's regenration capabilities are better than lithium chloride and calcium chloride.

\section{Conclusions}

The objective of this project was to reduce the dependency of the cooling systems on conventional and pollution causing energy sources. The utilization of liquid desiccant for air cooling is still emerging. Manipal has hot and humid summers and the temperature reaches values as high as $38^{\circ} \mathrm{C}$ and this provides an operative ground for the application of solar energy. The assistance of membranes decreases the carry-over of liquid desiccant into the air stream.

After an extensive literature review the liquid desiccants for the project were selected. Calcium chloride was selected because it is cheap and readily available whereas lithium chloride is the most commonly used desiccant. Potassium formate, a new desiccant, was chosen because of its regeneration capacity. The membrane was prepared to reduce the carry over and its topography was seen using the scanning electron microscope. The porosity was found using the IMAGEJ software. The effectiveness of the solar collector was calculated. Experimental Setup was fabricated using pump, solar collector, fans for inlet and outlet and membrane to reduce the carryover. The absolute and relative humidity of the three desiccants were found. The porous nature of the clay based membrane was accounted for with the help of IMAGEJ software. The solar collector has an efficiency value that is appropriate for the scale up of the set up. The fabricated experimental setup was proven to be effective upon running the experiment with the three chosen desiccants. 


\section{Acknowledgements}

The authors would like to prompt their deep appreciation and indebtness to the Department of Chemical Engineering, Manipal Institute of Technology, Manipal Academy of Higher Education, Manipal by entertaining our requirements and facilitating all the provisions utilized for the project.

\section{References}

1. Lowenstein, A., Slayzak, S. and Kozubal, E., 2006, July. "A zero carryover liquiddesiccant air conditioner for solar applications". ISEC.

2. Alizadeh, S., 2008. "A feasibility study of using solar liquid-desiccant air conditioner in Queensland, Australia". Journal of Solar Energy Engineering, 130(2), p.021005.

3. Gommed, K. and Grossman, G., 2004. "A liquid desiccant system for solar cooling and dehumidification". Transactions-american society of mechanical engineers journal of solar energy engineering, 126(3), pp.879-885.

4. Nia, F.E., Phelan, P.E. and van Paassen, D., 2011. "A new approach to study and compare the annual performance of liquid and solid desiccant cooling systems". Journal of Thermal Science and Engineering Applications, 3(2), p.021002.

5. Mei, L. and Dai, Y.J., 2008. "A technical review on use of liquid-desiccant dehumidification for air-conditioning application". Renewable and Sustainable Energy Reviews, 12(3), pp.662-689.

6. Katejanekarn, T., Chirarattananon, S. and Kumar, S., 2009. "An experimental study of a solar-regenerated liquid desiccant ventilation pre-conditioning system". Solar Energy, 83(6), pp.920-933.

7. Gandhidasan, P., 1990, August. "Analysis of a solar space cooling system using liquid desiccants". In Energy Conversion Engineering Conference, 1990. IECEC-90. Proceedings of the 25th Intersociety (Vol. 5, pp. 162-166).

8. Quinnell, J.A. and Davidson, J.H., 2013. "Buoyancy driven mass transfer in a liquid desiccant storage tank". Journal of Solar Energy Engineering, 135(4), p.041009.

9. Yin, Y. and Zhang, X., 2010. "Comparative study on internally heated and adiabatic regenerators in liquid desiccant air conditioning system". Building and Environment, 45(8), pp.1799-1807.

10. Daou, K., Wang, R.Z. and Xia, Z.Z., 2006. "Desiccant cooling air conditioning: a review". Renewable and Sustainable Energy Reviews, 10(2), pp.55-77.

11. Oliveira, Armando C., et al. "Thermal performance of a novel air conditioning system using a liquid desiccant". Applied Thermal Engineering 20 (13) (2000): 1213-1223.

12. Zhang, Li, Chaobin Dang, and Eiji Hihara. "Performance analysis of a no-frost hybrid air conditioning system with integrated liquid desiccant dehumidification". International journal of refrigeration 33(1) (2010): 116-124.

13. Li, Zhen, et al. "New type of fresh air processor with liquid desiccant total heat recovery".Energy and Buildings 37 (6) (2005): 587-593. 